\title{
Reabilitação Grupal: Expectativas e percepções de portadores de deficiência visual
}

\section{Grupal Rehabilitation: Expectations and perceptions of people with visual disabilities}

\author{
Mayla M. B. Monteiro' ${ }^{1}$, Rita de Cássia I. Montilha²
}

\begin{abstract}
RESUMO
Objetivos: Verificar características, expectativas e percepções de deficientes visuais, participantes de processo de reabilitação grupal. Métodos: Realizou-se estudo descritivo aplicando-se questionário por meio de entrevista à amostra não probabilística de pessoas com deficiência visual, de 12 anos e mais, usuários de serviço de reabilitação grupal do Centro de Estudos e Pesquisas em Reabilitação "Prof. Dr. Gabriel Porto" (CEPRE/FCM/UNICAMP) Foram aplicados dois instrumentos, um no início do processo de reabilitação e outro no final. Resultados: As amostras foram compostas por 26 e 14 usuários respectivamente, a diferença entre as duas amostras foi devido a algumas desistências no decorrer do processo de reabilitação, ou dificuldade de acesso aos usuários. Todos os usuários que responderam ao segundo questionário também responderam ao primeiro. Em relação às características dos usuários da amostra, a distribuição por sexo foi igual $(50,0 \%)$ do sexo masculino e feminino. A Baixa Visão foi o tipo de deficiência apresentada pela maioria (76.9\%), sendo a retinopatia diabética a causa mais mencionada (47,3\%). A maioria dos usuários declarou que esperava que a reabilitação fosse auxiliar a facilitar o cotidiano $(73,1 \%)$. Entre as percepções referentes ao processo de reabilitação destacou-se a melhora nas atividades da vida diária $(33,2 \%)$. Em relação às percepções acerca da reabilitação ter sido realizada em grupo a maioria $(71,4 \%)$ dos usuários declarou que achou boa esta estratégia terapêutica. Conclusão: Os usuários mostraram-se satisfeitos quando questionados sobre o processo de reabilitação no qual estavam inseridos, portanto este processo de reabilitação grupal consegue suprir as expectativas dos usuários referentes a este processo.
\end{abstract}

Palavras-chave: Reabilitação. Portadores de Deficiência Visual. Saúde de Grupos Específicos.

\section{Introdução}

Apesar do número de indivíduos portadores de Visão Subnormal (VSN) ser de três a cinco vezes maior que o de cegos, e o enfoque de reabilitação ser distinto, até pouco tempo atrás todos os deficientes visuais eram tratados como cegos. Os indivíduos com VSN, convivendo em instituições para cegos, portavam e

1. Fonoaudióloga. Mestre em 'Saúde, Interdisciplinaridade e Reabilitação' - Centro de Estudos e Pesquisa em Reabilitação "Prof. Dr. Gabriel O. S. Porto" - Faculdade de Ciências Médicas - Universidade Estadual de Campinas.

2. Doutora em Ciência Médicas. Docente do Curso de Fonoaudiologia da Universidade Estadual de Campinas, Centro de Estudos e Pesquisa em Reabilitação "Prof. Dr. Gabriel O. S. Porto" - Faculdade de Ciências Médicas - Universidade Estadual de Campinas.

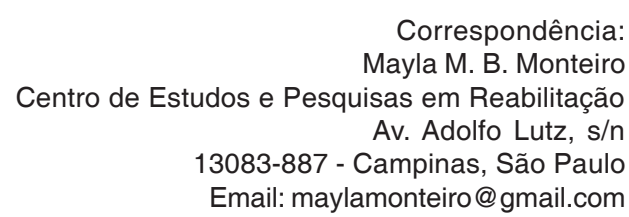

Artigo recebido em 11/11/2011 Aprovado para publicação em 15/03/2012 
adotavam os maneirismos próprios dos mesmos, inclusive para não serem segregados dentro das próprias instituições de que faziam parte. ${ }^{1}$

A importância que as pessoas conferem à sua visão e aos cuidados para protegê-la depende, em grande parte, de padrões sócios econômicos, de conhecimentos, de hábitos e crenças aprendidos culturalmente. ${ }^{2}$

$\mathrm{O}$ advento dos recursos ópticos especiais libertou estes indivíduos da condição de pessoas cegas, propiciando-lhes a oportunidade de, após um período de adaptação, desenvolverem seu potencial visual aplicando-o em suas atividades cotidianas. ${ }^{1}$

As necessidades visuais de cada pessoa variam de acordo com cada momento de sua vida, seja com a idade, com as atividades escolares, de lazer, de vida diária ou do trabalho. "A visão subnormal seria uma condição em que há uma diminuição da capacidade visual do indivíduo", impossibilitando-o de realizar tarefas rotineiras que antes eram feitas de maneira automática. ${ }^{3}$

De outro lado nem sempre o fácil acesso a serviços de saúde constitui garantia para a obtenção de estados de higidez. Assim, o conhecimento da existência de serviços de saúde também não significa a busca intencional de assistência. ${ }^{4}$

O Centro de Estudos e Pesquisa em Reabilitação "Prof. Dr. Gabriel O. S. Porto" (CEPRE) caracteriza-se por ser um centro que, desde sua criação desenvolve trabalhos direcionados a pessoas com deficiência visual e surdez, visando sua habilitação, educação e reabilitação, assim como de seus familiares.

A intervenção realizada no CEPRE dá-se por meio de equipes multidisciplinares das quais participam terapeuta ocupacional, psicólogo, assistente social, fonoaudiólogo, pedagogos especializados, linguistas e médicos. Os médicos que participam das intervenções realizadas no CEPRE são os que atuam nas parcerias realizadas entre o CEPRE e os departamentos de Otorrinolaringologia e Oftalmologia, Neurologia, Genética e Pediatria da Faculdade de Ciências Médicas da UNICAMP. A atuação dessa equipe permite uma visão mais abrangente do sujeito que chega ao CEPRE, já que cada profissional avalia-o dentro de seus conhecimentos, mas a atuação sobre ele ocorre de forma conjunta, levando-se em consideração o paciente como um todo.

A capacidade de ver proporciona as descobertas, os caminhos, a segurança, provocando a reação de proteção ao perigo, a orientação no espaço, o conhecimento visual do EU, das outras pessoas, das co- res, da natureza, das criações do homem. Proporciona também que haja a simbolização, isto é, a representação mental de todas as experiências visuais por meio de símbolos, de imagens. ${ }^{5}$

A visão também facilita conhecer todas as formas de comunicação não-verbal, de extrema importância para o relacionamento interpessoal, na medida em que olha-se para o outro e já pode-se compreendêlo através de suas atitudes corporais, de suas expressões faciais, de seu olhar, etc. Ela também permite estar a par de todos os acontecimentos e de informações gerais dadas pela escrita e pelos meios de comunicação visual. Ao mesmo tempo possibilita relacionar com outras pessoas de forma a carregar a primeira impressão, que é a aparência, ao invés de ater com o que elas são na essência. ${ }^{6}$

Para a realização de ações de saúde pública que dependem do comportamento das pessoas a que se destinam, torna-se de extrema importância conhecer previamente as maneiras de agir, sentir e pensar da comunidade-alvo dessas ações e o contexto onde se insere essa comunidade. ${ }^{2}$

Deste modo a tarefa da equipe de saúde, para uma comunicação eficiente, constitui-se da identificação do repertório de conhecimento e vocábulos comumente empregados pelas pessoas da comunidade.?

Levando-se em conta este dado, utilizou-se da pesquisa exploratória para obter uma visão mais realista acerca das respostas esperadas.

Compreende-se assim que ao se pretender realizar pesquisa sobre fatores humanos, recomenda-se o estudo prévio da realidade, na fase de planejamento da pesquisa, com a finalidade principal de elaborar um instrumento baseado nas experiências reais dos sujeitos, no seu vocabulário e ambiente de vida. ${ }^{8}$ Este estudo prévio é chamado de "pesquisa exploratória".

O estudo exploratório permite, portanto, aliar as vantagens de se obter os aspectos qualitativos das informações à possibilidade de quantificá-lo posteriormente. Esta associação realiza-se em nível de complementaridade, possibilitando ampliar a compreensão do fenômeno em estudo. ${ }^{9}$

Apesar dos recursos com que se pode contar atualmente para evitar a perda da visão, a cada dia muitas pessoas ficam cegas por doenças, acidente ou velhice. Para uma pessoa com visão normal, a perda repentina de seu mais precioso sentido é muito difícil. Principalmente se considerarmos que em nosso mundo cada vez mais orientado visualmente, ninguém conta com a possibilidade de ficar cego. ${ }^{10}$ 
A reabilitação visual visa auxiliar o portador de deficiência visual em atividades rotineiras, nas quais agora encontra dificuldade em realizar.

Desde o início o terapeuta deve estar disposto a assumir um papel mais ativo. No primeiro contato, na sala de espera, o terapeuta deve anunciar sua presença em voz alta, e deve estar pronto para tocar o paciente e permitir que este o toque, deixando que ele segure seu braço com firmeza. O terapeuta deve saber que comportamento como gesticular, ou expressão facial podem estar ausentes ou distorcidos no paciente cego. Portanto, ele deve aprender a traduzir em palavras as emoções visuais. ${ }^{10}$

Além da presença do terapeuta no processo de reabilitação, um apoio central, a família e a presença de alguém que possa dar força e suporte são importantes para continuar o processo de desenvolvimento na ajuda e não nas mudanças sonhadas e desejadas, mas nas possíveis. ${ }^{5}$

De acordo com as considerações apresentadas e visando ampliar os conhecimentos em relação às expectativas da clientela de portadores de deficiência visual durante o processo de reabilitação dentro da terapia grupal, o presente estudo tem por objetivos descrever características de deficientes visuais, participantes de grupo de reabilitação do CEPRE; verificar expectativas de deficientes visuais participantes de grupo de reabilitação em relação ao processo de reabilitação e verificar percepções de deficientes visuais, que participam de grupos de reabilitação do CEPRE, em relação às modificações no seu cotidiano decorrentes da sua participação nesse grupo.

\section{Material e Método}

A investigação foi realizada por meio de levantamento de percepções.

A população deste estudo foi constituída por indivíduos de 12 anos e mais portadores de deficiência visual, congênita ou adquirida, atendidos no Programa de Adolescentes e Adultos Deficientes Visuais do CEPRE no período de fevereiro a dezembro de 2005.

As variáveis utilizadas para a elaboração dos questionários são apresentadas a seguir:

- Características pessoais: sexo, idade, ocupação, cidade de nascimento, escolaridade, tipo de deficiência visual, idade do aparecimento do problema oftalmológico, origem do problema oftalmológico.

- Aspectos referentes ao processo de reabilitação: expectativas dos pacientes de como ocorrerá o pro- cesso de reabilitação, conhecimento dos pacientes em relação ao processo de reabilitação, conhecimento dos pacientes em relação à terapia grupal e sua contribuição no processo de reabilitação, percepção dos pacientes em relação à contribuição do atendimento grupal para o seu processo de reabilitação, contribuição do grupo de reabilitação para: escolarização; profissionalização; lazer; convívio com familiares; atividades cotidianas; avaliação do processo de reabilitação grupal.

Foi realizado estudo exploratório para a elaboração de dois instrumentos de medida. Primeiramente foram realizadas entrevistas abertas com os portadores de defiiência que fazem parte de Programa de Adolescentes e Adultos Deficientes Visuais do CEPRE. Após esta coleta de dados realizada através do estudo exploratório, foram elaborados dois questionários contendo perguntas e respostas.

O primeiro questionário foi aplicado antes do início do grupo de reabilitação, visando enfocar as características pessoais e expectativas dos usuários referentes a este serviço. O segundo questionário foi aplicado quando os indivíduos estavam terminando os atendimentos do grupo de reabilitação, visando enfocar as percepções dos usuários referentes ao processo de reabilitação.

$\mathrm{O}$ pré-teste tem a finalidade de aperfeiçoar a forma do instrumento, e integrar-se, gradualmente, nas etapas do estudo exploratório. Constitui prova necessária para assegurar confiança e validade dos dados a serem obtidos na pesquisa. ${ }^{8}$

Neste estudo, o pré-teste foi realizado aplicando-se o questionário estruturado aos portadores de deficiência visual que fazem parte do Programa de Adolescentes e Adultos Deficientes Visuais do CEPRE, atendidos durante o ano de 2005.

A coleta de dados foi realizada em dois momentos. No primeiro momento, os usuários foram entrevistados no início do processo de reabilitação. Eles responderam a um questionário que continha perguntas pertinentes às expectativa perante ao processo de reabilitação. No segundo momento, os usuários responderam a um questionário com perguntas pertinentes às percepções que ocorreram durante o processo de reabilitação. Os questionários foram por meio de entrevista individual dos indivíduos que são atendidos no Programa de Adolescentes e Adultos Deficientes Visuais do CEPRE. Esta entrevista foi gravada e depois analisada para que se pudesse levantar as variáveis mais características da clientela selecionada. 
O CEPRE foi o local onde aconteceram as entrevistas, devido a viabilidade de acesso da clientela.

Antes de iniciar a aplicação do questionário com cada cliente foram explicados os objetivos da pesquisa, assim como foram assegurados o anonimato e a confidencialidade das informações.

Para a análise dos resultados Foi criado um banco de dados no programa EPI INFO versão 6.04. A análise estatística foi realizado com acessoria de profissionais especializados na área.

\section{Resultados}

Foram entrevistados 26 sujeitos com o primeiro questionário, e 14 com o segundo. O primeiro questionário foi aplicado antes do início do grupo de reabilitação, visando enfocar as características pessoais e expectativas dos usuários referentes a este serviço. O segundo questionário foi aplicado quando os indivíduos estavam terminando os atendimentos do grupo de reabilitação, visando enfocar as perspectivas dos usuários referentes ao processo de reabilitação.

A distribuição por sexo apresenta igualdade de proporções entre homens e mulheres (50\%). A média de idade é de 40,9 anos; a maioria dos usuários reside em outras cidades do Estado de São Paulo $(65,4 \%)$.

Em relação à escolaridade a maioria dos usuários concluiu ou está concluindo o ensino fundamental $(42,5 \%)$.

Em relação à situação ocupacional a maioria dos usuários não está trabalhando no momento $(80,8 \%)$.

No que diz respeito ao conhecimento a respeito da própria deficiência visual, $23,1 \%$ referem visão subnormal e $76,9 \%$ referem cegueira, predominando a origem adquirida $(76,9 \%)$.

Para a questão do conhecimento do problema oftalmológico a maioria $(73,1 \%)$ afirmou conhecer a causa da deficiência visual, predominado a retinopatia diabética $(50,6 \%)$ como o problema mais frequente, seguido de glaucoma e catarata $(12,9 \%)$, retinose pigmentar $(8,6 \%)$, aniridia, alta miopia, atrofia do nervo óptico, ceratocone e deslocamento da retina $(4,3 \%)$; e a diabetes $(59,1 \%)$ como a causa mais frequente.

A principal percepção descrita pelos usuários sobre sua deficiência visual é a da percepção de claridade $(34,6 \%)$.

Em relação às expectativas dos usuários referentes ao processo de reabilitação a maioria $(69,2 \%)$ afirmou que esperava que a reabilitação fosse realizada em grupo; e "melhorar" foi apontado pela maio- ria $(22,2 \%)$ como a principal expectativa referente ao processo de reabilitação.

A maioria $(53,8 \%)$ dos usuários afirmou que acha que a reabilitação é um lugar para conhecer pessoas com problema visual. Pouco mais da metade dos usuários $(61,5 \%)$ declarou estar achando "muito boa" a reabilitação grupal; e a grande maioria $(73,1 \%)$ afirmou que espera que a reabilitação facilite seu cotidiano.

Os usuários manifestaram-se favoráveis ao fato do processo de reabilitação ser realizado em grupo.

Os usuários manifestaram ter percebido uma maior modificação no seu cotidiano (85,7\%), seguido nos estudos $(21,4 \%)$. Entre as modificações do cotidiano, a melhora nas AVDs (atividade de vida diária) apresentou-se como a que sofreu mais modificações $(33,3 \%)$. Entre as modificações ocorridas no relacionamento com as famílias, foram citados melhora na relação e diminuição dos cuidados excessivos. A percepção de mudanças ocorridas em relação ao lazer deu-se principalmente na locomoção e socialização.

Em relação à reabilitação ser realizada em grupo a maioria dos usuários $(71,4 \%)$ opinou como sendo essa uma boa estratégia de realização do processo.

A maioria dos usuários $(28,4 \%)$ apontou a locomoção como sendo uma das sugestões para a melhoria do processo de reabilitação.

Em relação à sua auto-avaliação dentro do grupo de reabilitação, todos os usuários afirmaram que acharam seu desempenho bom.

\section{Discussão}

O levantamento de percepções constitui modalidade de pesquisa frequentemente empregada no setor da saúde. Trata-se de um tipo de investigação científica em que se estuda a realidade de forma como se apresenta, sem o propósito de estabelecer relação causal entre as variáveis. ${ }^{11}$

Este trabalho foi realizado no CEPRE. Na presente amostra de 26 pacientes, percebeu-se que não houve diferença em relação ao sexo.

Apesar de nos países desenvolvidos, $75 \%$ da população com deficiência visual constituir-se de indivíduos com idade acima de 60 anos ${ }^{12}$; no presente trabalho, o grupo etário que prevaleceu foi o de adultos com a faixa etária de 40-60 anos com 38,4\% dos casos.

Analisando os dados sobre o trabalho, vemos que somente uma pequena porcentagem dos usuários continua trabalhando mesmo após a confirmação de sua deficiência visual. 
A limitação sensorial impõe um percurso de obstáculos quanto à escolha e ao engajamento profissional dos cidadãos, parcial ou completamente cegos. É sabido que no Brasil, o mercado de trabalho, está cada vez menos favorável e mais competitivo. O desemprego em massa, a instabilidade econômica, a concorrência acirrada (a proporcionalidade candidato/ vaga) e a absorção de mão-de-obra especializada são fatores que excluem cada vez mais o deficiente visual do mercado de trabalho. ${ }^{13}$

Após a confirmação da cegueira, o afastamento do trabalho é a situação mais frequente enfrentada pelo deficiente visual. A cegueira adquirida configura um estado de deficiência permanente, o que justifica a aposentadoria precoce legalmente definida. Neste caso o trabalhador tem o direito de usufruir de licenças médicas sucessivas para o tratamento até conseguir seu afastamento definitivo do trabalho. Raramente, o empregador propicia ao empregado a oportunidade de sua reintegração profissional, sendo mais fácil e mais prático aplicar a lei que é considerada um justo benefício. O processo de reintegração profissional costuma ser lento e trabalhoso: depende da disponibilidade e da abertura por parte do empregador e de fatores intrínsecos e extrínsecos à vida do empregado. Quando isto acontece, o trabalhador deixa de executar tarefas visuais para assumir outras atividades, de acordo com ajustes e adaptações programadas, devendo ser preparado para o remanejamento. ${ }^{13}$

A inserção profissional das pessoas com cegueira congênita ou adquirida prematuramente é muito mais difícil. Alguns vivem completamente tutelados por seus familiares ou por instituições filantrópicas. Poucos conseguem trabalhar com vínculo empregatício, especialmente em ocupações que escolheram. Aqueles, cujo poder aquisitivo o permite, ocupam posição de proprietários ou empregadores, mais isso dificilmente acontece. Mesmo aqueles que continuam tentando se inserirem no mercado de trabalho encontram dificuldades por todo o percurso, já que quase nunca encontram condições apropriadas e quase sempre precisam convencer aos outros de suas potencialidades. Assim, a aposentadoria por invalidez que, aparentemente representa um benefício, torna-se também um instrumento de estagnação e de exclusão. ${ }^{14}$

Existem programas de incentivo à absorção de mão-de-obra de pessoas com deficiência visual. Porém as opções são poucas e não necessariamente, o indivíduo tem interesse ou vocação para exercer uma dessas atividades. Muitos acabam por sufocar ou su- blimar suas aspirações e potencialidades, adaptandose às alternativas possíveis para não ficarem sem trabalho. Não se trata de compreender que a deficiência não deve servir como critério de exclusão ou de contratação de pessoal, desconsiderando-se a qualificação e competência para o trabalho. ${ }^{13}$

Uma pessoa com deficiência visual é vista quase sempre como alguém muito dependente que precisa ser guiado, protegido e amparado. A falta de visão, a priori, é percebida como ponto frágil e vulnerável, detonando atitudes e expectativas extremas que coisificam as pessoas não videntes. Essa e outras barreiras são quase intransponíveis e podem obstaculizar o acesso dos deficientes visuais ao mercado de trabalho. ${ }^{13}$

Neste trabalho encontrou-se o predomínio de indivíduos com Baixa Visão (BV) (76,9\%). Apesar do número de indivíduos portadores de $\mathrm{BV}$ ser de três a cinco vezes maior que o de cegos, e o enfoque de reabilitação ser distinto, até pouco tempo atrás todos os deficientes visuais eram tratados como cegos. Os indivíduos com BV, convivendo em instituições para cegos, portavam e adotavam os maneirismos próprios dos mesmos, inclusive para não serem segregados dentro das próprias instituições de que faziam parte. ${ }^{1}$

Com relação à origem do problema oftalmológico, 76,9\% dos casos de deficiência visual foi adquirida e $23,1 \%$ congênita. A retinopatia diabética apresentou-se nesse trabalho como sendo o problema visual mais comum entre os usuários do programa $(47,3 \%)$.

A retinopatia diabética é uma das principais causas de cegueira, fazendo parte ao lado das nefropatias, vasculopatias e neuropatias, do conjunto de complicações mais frequentes dos pacientes com Diabetes Mellitus que, com o aumento da sobrevida, manifestam progressivamente a doença com maior incidência e gravidade. A retinopatia diabética apresenta comportamento diferente nos pacientes insulino-dependentes, sendo que o controle metabólico adequado tente a retardar o aparecimento e diminuir a gravidade das alterações fundoscópicas que, no entanto, quando já existentes não se modificam significativamente com a normalização da glicemia. ${ }^{15}$

Em âmbito mundial a retinopatia diabética vem se tornando um problema de saúde pública. Após 15 anos de diabetes a prevalência de retinopatia entre os portadores diabetes mellitus insulino-dependentes é de $97 \%$ e nos diabéticos não insulino-dependentes de $80 \%{ }^{4}$

$\mathrm{O}$ diabetes mellitus é uma doença com características sistêmicas que ocorre com cerca de 6 a $7 \%$ 
da população brasileira e se caracteriza por causar lesões microangiopáticas. ${ }^{16}$

O diabetes mellitus está entre as principais causas de cegueira irreversível no Brasil e no mundo. As complicações oculares são frequentes e graves no paciente diabético, e a retinopatia diabética é a mais comum, presente em 29 a $40 \%$ dos doentes diabéticos. ${ }^{16}$

Estudos têm mostrado que o tratamento da retinopatia diabética é efetivo na prevenção da perda visual, e que a detecção precoce e acompanhamento são importantes para o bom prognóstico. ${ }^{16}$

$\mathrm{O}$ atual conceito de prevenção da cegueira ampliou-se no seu enunciado, enfatizando-se a preservação da visão. Neste sentido, relaciona-se estreitamente à qualidade de vida do ser humano, na qual desempenha importante função a capacidade visual. ${ }^{17}$

A atuação no nível primário de prevenção, como a melhoria das condições gerais de via dos indivíduos e comunidades, evitaria um crescente aumento no nível da população portadora de deficiência visual. ${ }^{17}$

Em relação às principais causas de deficiência visual, a Organização Mundial de Saúde (OMS) classifica os países e regiões de acordo com o nível de assistência médica estendida à população. Por esse critério o Brasil poderia ser classificado como país em fase intermediária de desenvolvimento, apresentando como causas de cegueira: glaucoma, tracoma, oncocercose, xeroftalmia, catarata e traumatismo. ${ }^{18}$

A importância do diagnóstico das causas mais frequentes de baixa visual reflete no planejamento e realização de programas de saúde pública em oftalmologia que visem priorizar ações relacionadas à prevenção de estados conducentes à cegueira e à incapacidade visual, a promoção de saúde ocular, a organização da assistência oftalmológica e a reabilitação de deficientes visuais. ${ }^{17}$

A respeito das expectativas dos portadores de deficiência visual entrevistados, observou-se predomínio em relação à melhora de uma maneira geral $(22,2 \%)$.

O interesse em aprender coisas novas também ressalta-se entre as expectativas $(53,8 \%)$.

Quanto à conduta reabilitacional indicada, percebeu-se que proporção apreciável dos usuários declarou estar satisfeito com o processo de reabilitação $(61,5 \%)$.

A motivação para se reabilitar é considerada pelos profissionais de reabilitação com um importante determinante no desempenho do paciente. Porém poucos estudos até hoje tentaram fazer uma análise por- menorizada dos fatores implicados na motivação de pacientes em programas de reabilitação. ${ }^{19}$

Durante um estudo sobre motivação ${ }^{19}$, afirmouse que temas como estes: confiança em realizar uma boa melhora, visão sobre o relacionamento com os profissionais, idéias sobre fatores importantes da reabilitação, idéias sobre o papel do paciente na reabilitação, idéias sobre a natureza e objetivo da reabilitação, sentimentos sobre que tipo de vida era desejada após a perda da visão; eram discutidos com o pacientes e geraram uma maior adesão ao processo de reabilitação.

Este estudo ${ }^{19}$ teve como conclusão de que pacientes identificados como sendo de alta motivação para a reabilitação se mostraram mais engajados com os objetivos e métodos da reabilitação assim como conseguiram compreender melhor todo o processo. Muitos pacientes consideravam como progresso na reabilitação, o desenvolvimento da independência nas atividades do dia-a-dia.

A principal opinião dos usuários sobre a reabilitação ter sido feita em grupo foi positiva $(71,4 \%)$. Segundo as respostas dadas, grande parte dos usuários referiu ser muito produtiva a reabilitação ser realizada em grupo, já que deste modo há possibilidade de conhecer pessoas como o mesmo problema $(53,8 \%)$, levando à troca de experiências e conversas sobre suas dificuldade e superações.

"Um grupo seria um conjunto de pessoas em uma ação interativa com objetivos compartilha$d o s " .{ }^{20}$ Pensando assim, tem-se que para podermos chamar um conjunto de pessoas de grupo, precisa-se que elas tenham um objetivo em comum. O que certamente acontece durante o processo de reabilitação que é realizado em grupo. Pode-se afirmar que os objetivos comuns aos usuários atendidos no CEPRE estendem-se sobre atividades da vida diária, visando sempre uma menor dependência.

Dividir suas angústias e expectativas pode ser um bom método para a aceitação de sua condição. Na reabilitação grupal, a troca de experiências entre os usuários enriquece ainda mais o processo; já que este consiste em relatos de pessoas que vivenciam experiências parecidas.

A maioria dos usuários apontou como sendo a locomoção uma sugestão para a melhoria do processo de reabilitação $(28,4 \%)$. Este resultado era esperado já que a locomoção apresenta-se como sendo um dos aspectos mais limitantes do adulto que perde a visão.

A perda da mobilidade decorrente da perda da visão apresenta importância fundamental, porque 
significa mais do que andar significa a liberdade de ir de um lugar para outro, mediante todos os meios possíveis.

Essa perda enfrentada pelos portadores de deficiência visual acarreta mudanças profundas, não só em relação a sua locomoção, como também em relação a sua vida social, já que necessitam aprender a conviver com suas necessidades e carências dentro de um mundo que possui pouca estrutura para acolhê-los.

Em relação à sua auto-avaliação dentro do grupo de reabilitação, todos os usuários afirmaram que acharam seu desempenho bom (100\%).

No presente estudo, observou-se que os usuários do programa de reabilitação grupal oferecido pelo CEPRE encontram-se satisfeitos como pôde-se notar com suas percepções, apesar das expectativas apresentadas pelos usuários serem divergentes.

Face aos resultados deste estudo, conclui-se que os usuários demonstraram que vêem o processo de reabilitação como um lugar para adquirir conhecimentos novos que vão auxilia-lo em sua vida cotidiana e que possuem uma opinião favorável em relação ao processo de reabilitação.

\section{Conclusão}

Os usuários mostraram-se satisfeitos quando questionados sobre o processo de reabilitação no qual estavam inseridos. Suas expectativas e perceptivas encontraram-se em grande parte alcançadas ou superadas. Por se tratar de um processo de reabilitação diferenciado que utiliza o grupo como um instrumento terapêutico, esperava-se que os usuários opinassem a respeito dessa prática. Os usuários responderam afirmativamente para este recurso e também para todos os outros utilizados durante o processo, assim como para a melhoria em seu cotidiano/vivência que a socialização por meio do grupo proporcionava. Por ter sido bem sucedido, a maioria dos usuários declarou que gostaria que o tempo do processo fosse aumentado. A sugestão da maioria dos mesmos era que houvesse uma maior ênfase no referente à locomoção. Sugerese, então, que atividades que visem este aspecto fossem inseridas no processo de reabilitação visual do CEPRE.

A fonoaudiologia encontra-se em expansão. Deste modo, há pouca literatura sugerindo a prática do fonoaudiólogo na reabilitação de deficientes visuais. Mas como é sabido, a Fonoaudiologia trata de um aspecto importante para a socialização do ser humano: a comunicação. Seja esta, leitura e escrita, ou na fala.

Percebe-se assim que há um lugar, e que este mostra-se essencial, para o fonoaudiólogo dentro de um processo de reabilitação visual. O auxílio na leitura e na escrita, não somente das letras, mas da construção de um contexto, pode e deve ser designado ao fonoaudiólogo dentro desse processo. Além do mesmo na construção de material que auxilie a reabilitação.

Além da visualização os sinais gráficos (letras/ números), o usuário precisa aprender a internalizar e distinguir o significado de cada um, conseguir agrupalas formando palavras e saber sua utilização dentro de um contexto qualquer. A aprendizagem da leitura e escrita dentro de um processo de reabilitação visual pode vir a ser uma motivação maior do usuário para usufruí-lo com mais prazer e frequência. Este recurso visaria como resultado uma maior autonomia por parte do deficiente visual, auxiliando a realizar tarefas de leitura e escrita cotidianas que antes teriam que ser realizadas por outras pessoas.

\section{Agradecimentos}

Ao Centro de Estudos e Pesquisa em Reabilitação "Prof. DR. Gabriel O. S. Porto' pela disponibilidade de realização da pesquisa.

A FAPESP, pelo financiamento da mesma.

\footnotetext{
ABSTRACT

Purpose: Check characteristics, expectations and perceptions of the visually impaired, participants of the rehabilitation process group. Methods: There was descriptive study according to questionnaire through the interview not probability sample of people with visual impairments of 12 years and more, users of rehabilitation service group the Centre for Studies Rehabilitation and Research in "Prof. Dr. Gabriel Port" (CEPRE/FCM/UNICAMP). Two instruments were used, one early in the process of rehabilitation and another at the end. Results: The samples were composed of 26 and 14 users respectively, the difference between the two samples was due to some dropouts in the process of rehabilitation, or difficulty of
} 
access to users. All users who answered the second questionnaire also responded to the first. For users characteristics of the sample, the breakdown by sex was equal (50.0\%) male and female. The Low Vision was the type of disability presented by the majority $(76.9 \%)$, with diabetic retinopathy the most mentioned (47.3\%). Most users said he expected that rehabilitation would help to ease the daily life (73.1\%). Among the perceptions concerning emphasizing the process of rehabilitation is the improvement in activities of daily living (33.2\%). For perceptions about the rehabilitation group has been held in the majority $(71.4 \%)$ of users said it felt good therapeutic strategy. Conclusion: Users have to be satisfied when asked about the rehabilitation process in which they were inserted, so this process of rehabilitation group can meet the expectations of the user regarding this process.

Keywords: Rehabilitation. Visually Impaired Persons. Health of Specific Groups.

\section{Referências Bibliográficas}

1. Kara-José N, Carvalho KMM, Pereira VL, Venturini NHB, Gaspareto MERF, Gushiken MT. Estudo retrospectivo dos primeiros 140 casos atendidos na Clínica de Visão Subnormal do Hospital de Clínicas da UNICAMP. Arq Bras Oftalmol. 1988; 51:65-9.

2. Temporini ER. Pesquisa de oftalmologia em saúde pública: considerações metodológicas sobre fatores humanos. Arq Bras Oftalmol. 1991; 54: 279-81.

3. Tayah D, Rehder JRCL. Custo-beneficio da implantação do serviço de visão subnormal do Instituto de Olhos do ABC. Rev Bras Oftalmol. 2004; 63: 265-73.

4. Silva VB, Temporini ER, Moreira Filho, DC, Kara-Jose N. Tratamento da retinopatia diabética: percepções de pacientes em Rio Claro (SP) - Brasil. Arq Bras Oftalmol. 2005; 68: 363-8.

5. Bruno MMG. O desenvolvimento integral do portador de deficiência visual: da intervenção precoce à integração escolar. Newswork, 1993:144.

6. Nobre MIRS. Atendimento de estimulação em serviço de visão subnormal: características de usuários, opinião e conduta de mães. Dissertação. Campinas (SP): Faculdade de Ciências Médicas - Universidade Estadual de Campinas; 1997.

7. Piovesan A, Temporini ER. Pesquisa exploratória: procedimento metodológico para o estudo de fatores humanos no campo da saúde pública. Rev Saúde Pública. 1995; 39:318-25.

8. Temporini ER. Saúde do escolar: conduta e opinião de professores do sistema de ensino do Estado de São Paulo. Tese. São Paulo (SP): Universidade Estadual de São Paulo; 1986.

9. Minayo MCS, Sanches O. O quantitativo-qualitativo: oposição ou complementaridade? Cad Saúde Pública. 1993; 9:239-62.
10. Barczinski MCC. Reações psicológicas à perda da visão. 2005 Disponível em: http://www.portaldaretina.com.br. Acesso em 25 de agosto de 2010.

11. Temporini, ER, Kara-Jose N. Níveis de prevenção de problemas oftalmológicos: Propostas de intervenção. Arq Bras Oftalmol. 1995; 58:189-94.

12. Organização Mundial de saúde. $O$ atendimento de crianças com baixa visual. Programa para a prevenção de cegueira da OMS. Bangok: OMS. 1994:32-9.

13. Sá ED. O deficiente visual e o trabalho competitivo. Rev Bras Educ Espec. 1994; 1: 137-9.

14. Anache AA. O deficiente e o mercado de trabalho: concessão ou conquista? Rev. bras. educ. espec. [online]. 1996; 2: 119-26.

15. Farah ME. Retinopatia diabética. 2003. Disponível em: http:// www.portaldaretina.com.br. Acesso em 03 de setembro de 2010.

16. Souza EV, Souza NV, Rodrigues, MLV. Retinopatia diabética em pacientes de um programa de atendimento multidisciplinar do Hospital das Clínicas de Ribeirão Preto - USP. Arq Bras Oftalmol. 2004, 67: 433-6.

17. Rodrigues MLV. Prevenção de perdas visuais. Medicina (Ribeirão Preto) 1997; 30: 84-9.

18. Juarez BM. A motivação para a reabilitação em pacientes. Disponível em: http://www.boasaude.com.br. Acesso em 03 de setembro de 2010.

19. Osorio LC. Grupos, Teorias e Práticas - Acessando a era da grupalidade. Porto Alegre: Artmed Sul, 2000. 


\section{ANEXO 1 - Questionário 1}

1) Sexo : ( ) Feminino ( ) Masculino

2) Quantos anos completos você tem?

3) Qual a cidade que você nasceu?

4) Em que estado fica esse esta cidade?

5) Em qual cidade você vive?

6) Com quem você mora? ( ) Pais/irmãos ( ) Conjugue ( ) Conjugue/ filhos ( ) Filhos

( ) Outros / Quais?

7) Você estudou: ( ) sim ( ) não?

Se sim, até que série você estudou?
( ) primário incompleto
( ) primário completo
( ) ensino fundamental incompleto
( ) ensino fundamental completo
( ) ensino médio incompleto
( ) ensino médio completo
( ) superior incompleto
( ) superior completo

8) Você atualmente trabalha? ( ) Sim ( ) Não (Passe para a questão 10)

9) Qual o trabalho que você faz no momento?

10) Por causa do seu problema de vista, hoje você enxerga como?
( ) Pouco
( ) Muito Pouco
( ) Nada

11) Você sabe o nome do seu problema de vista, ( ) Sim ( ) Não Se sim, qual é?

12) Fale sobre o seu problema de vista

13) Você sabe por que você teve esse problema de vista, o que causou?

14) Quantos anos você tinha quando ficou com esse problema de vista?

15) O que você espera que aconteça durante a reabilitação?

16) O que você está achando da reabilitação? 
17) O que você acha que é reabilitação?

- Lugar para conhecer pessoas com o mesmo problema
( ) Sim ( ) Não
( ) Sim ( ) Não
( ) Sim ( ) Não
( ) Sim
( ) Não

- Aprender coisas novas

- Ter novas experiências

- Outra coisa que eu não falei?

- Qual?

18) Como você acha que a reabilitação vai ajudar no seu problema de vista?

- Conhecer pessoas com um problema semelhante ao seu

( ) Sim ( ) Não

- Aprender a fazer coisas com mais facilidade

( ) $\operatorname{Sim}$ ( ) Não

- Aprender a mexer na cozinha

( ) Sim ( ) Não

- Vai curar o problema visual

( ) Sim ( ) Não

- Passar o tempo

( ) Sim ( ) Não

- Outra coisa que eu não falei?

( ) Sim

( ) Não

- Qual?

19) Você esperava que a reabilitação fosse feita em grupo? ( ) Sim ( ) Não

20) O que você acha da reabilitação ser feita em grupo?
- Bom
( ) Sim
( ) Não
- Indiferente
( ) Sim
( ) Não
- Ruim
( ) Sim
( ) Não
- Não tem opinião
( ) Sim
( ) Não 


\section{Anexo 2 - QUESTIONÁRIO 2}

1) Sexo : ( ) Feminino ( ) Masculino

2) Quantos anos completos você tem?

3) Qual a cidade que você nasceu?

4) Em que estado fica esse esta cidade?

5) Em qual cidade você vive?

6) Com quem você mora? ( ) Pais/irmãos ( ) Conjugue ( ) Conjugue/ filhos ( ) Filhos

( ) Outros / Quais?

7) Você estudou: ( ) sim ( ) não?

Se sim, até que série você estudou?
( ) primário incompleto
( ) primário completo
( ) ensino fundamental incompleto
( ) ensino fundamental completo
( ) ensino médio incompleto
( ) ensino médio completo
( ) superior incompleto
( ) superior completo

8) Você atualmente trabalha? ( ) Sim ( ) Não (Passe para a questão 10)

9) Qual o trabalho que você faz no momento?

10) Por causa do seu problema de vista, hoje você enxerga como?
( ) Pouco
( ) Muito Pouco
( ) Nada

11. Você sabe o nome do seu problema de vista, ( ) Sim ( ) Não ECA: Qual? Qual?

12) Fale sobre o seu problema de vista.

13) Você sabe por que você teve esse problema de vista, o que causou?

14. Quantos anos você tinha quando ficou com esse problema de vista?

15. Você acha que ocorreram modificações no seu dia a dia durante esse período que está vindo aqui fazer reabilitação?
( ) Sim
( ) Não
ECA, Qual(is)?
Qual(is)? 
16. E com relação ao relacionamento com a família, você sentiu mudanças?
( ) Sim
( ) Não
ECA, Qual(is) mudanças?

Mudanças:

17. E com relação ao lazer, você sentiu mudanças?
( ) Sim
( ) Não ECA, Qual(is) mudanças?

Mudanças:

18. Você atualmente está estudando? ( ) Sim ( ) Não (Passe para a questão 19) ECA: Notou algum tipo de mudança em relação aos estudos durante o período de reabilitação?
( ) Sim
( ) Não
ECA, Qual(is) mudanças?

Mudanças:

19. Você atualmente está trabalhando? ( ) Sim （ ) Não (Passe para a questão 20) ECA: notou algum tipo de mudança em relação à esta atividade durante o período de reabilitação?

( ) Sim ( ) Não ECA, Qual(is) mudanças? Mudanças:

20. O que você acha da reabilitação estar sendo feita/ter sido feita em grupo?

Por quê?

21. O que você falar pode contribuir para melhorar o atendimento de outra pessoa com necessidades parecidas com as suas. O que você acha que poderia ser melhorado nesse processo de reabilitação?

22. Como você avalia seu processo de reabilitação dentro do grupo?
( ) Bom
( ) Indiferente
( ) Ruim
( ) Não tem opinião 